\title{
PENGARUH PERCEIVED ORGANIZATIONAL SUPPORT DAN EMPLOYEE ENGAGEMENT TERHADAP KINERJA KARYAWAN
}

\author{
Septi Diana \\ Universitas Negeri Surabaya \\ septi.17080574007@mhs.unesa.ac.id \\ Agus Frianto \\ Universitas Negeri Surabaya \\ agusfrianto@unesa.ac.id
}

Abstract

This study aims to determine how the effect of perceived organisational support and employee engagement on the performance of employees. This study uses quantitative research with a population of employees at UD. Zacyndo safety shoe factory in Tuban and Mojokerto regency. This study using a sample of 45 employees. Data collection techniques were carried out by collecting primary data through the distribution of online questionnaires and using secondary data collection through documentation of organisational activities/events and other written sources of information as writing reference materials. Data were analysed using multiple regression through SPSS version 24. The result showed that perceived organisational support had a negative and insignificant effect on employee performance, employee engagement had a significant and positive effect on employee performance, and perceived organisational support and employee engagement had a positive and significant effect on employee engagement. UD. Zacyndo may improve POS better by paying attention to employee welfare to produce maximum performance. In addition, improve strong relationships with each employee may help the organisation to achieve the intended goals.

Keywords: employee engagement; employee performance; perceived organizational support.

\section{PENDAHULUAN}

Dunia mengalami perubahan besar pada sektor ekonomi setelah adanya revolusi industri 4.0 dengan cyber physical yang mana membuat persaingan semakin ketat dan kompetitif (Prastyo \& Frianto, 2020). Selain itu, revolusi industri 4.0 membawa perubahan perkembangan teknologi digitalisasi. Untuk itu, organisasi ataupun perusahaan perlu dukungan dari sumber daya manusia (SDM) yang mempunyai kualitas serta kuantitas untuk mencapai tujuan (Saretta, 2019). SDM merupakan aset yang penting karena menjadi penentu keberlangsungan hidup perusahaan. sehingga harus terus dilatih dan ditingkatkan kemampuannya baik dari segi kualitas maupun kuantitas (Wahyani, 2020). Dengan adanya pengelolaan SDM yang baik, pencapaian tujuan perusahaan akan lebih efisien (Wahyuni, 2019) .

Cintani \& Noviansyah (2020) menyatakan kinerja merupakan hasil kerja yang diperoleh karyawan atau perilaku sesungguhnya yang dihasilkan karyawan dalam peranannya di perusahaan. Upaya peningkatan kinerja karyawan hendaklah diperhatikan oleh perusahaan dengan terus memberikan pelatihan dalam berperilaku kerja serta bersikap profesional (Nadeak, 2019). Informasi mengenai kinerja pegawai merupakan aspek yang begitu penting digunakan sebagai bahan evaluasi untuk mengukur seberapa jauh proses kinerja yang sudah dilakukan karyawan pada perusahaan selama ini apakah sudah berlangsung sesuai dengan visi perusahaan (Aziz, 2018).

Di perusahaan, karyawan mencoba memelajari, mengingat, dan memerhatikan, dan berharap ada dukungan yang diperoleh untuk mendukung peningkatan kinerja karyawan (Agustiningrum, 2016). Dukungan dari perusahaan kepada karyawannya dapat dilihat dari adanya perilaku adil antar karyawan, dukungan yang berasal dari supervisor untuk menyejahterakan karyawannya, penghargaan yang diberikan oleh perusahaan untuk karyawan serta kondisi lingkungan sekitar tempat kerja yang aman dan nyaman dirasakan oleh karyawan (Mursidta, 2017). Karyawan juga ingin merasakan bahwa perusahaan mengakui jika dirinya telah ikut terlibat dalam keberhasilan yang telah tercapai sehingga dapat menimbulkan persepsi tentang baik buruknya perusahaan atau POS (Santoso \& Mangundjaya, 
Septi Diana \& Agus Frianto. Pengaruh Perceived Organizational Support dan Employee Engagement terhadap Kinerja Karyawan

2018). Ariarni \& Afrianty (2017) menyatakan perceived organizational support (POS) merupakan persepsi karyawan tentang seberapa jauh percaya bahwa kontribusi dan kesejahteraan dihargai oleh perusahaan. Untuk itu, perusahaan perlu mengoptimalkan dukungan terhadap karyawan supaya memiliki persepsi bahwa perusahaan telah menghargai kontribusi. Apabila karyawan beranggapan dukungan dari perusahaan yang telah diterima itu besar, persepsi positif akan muncul sehingga berdampak pada hasil kinerja. Fitria et al. (2018) menyatakan POS memiliki pengaruh langsung dan signifikan terhadap tingkat kinerja karyawan artinya semakin tinggi tingkat POS yang dimiliki maka hasil kerja semakin baik. Kinerja yang maksimal akan lebih banyak diberikan oleh pekerja dengan tingkat POS yang baik. Namun, ditemukan pernyataan yang bertentangan yakni menunjukkan POS berpengaruh negatif terhadap kinerja karyawan artinya semakin tinggi POS maka kinerja semakin rendah (Agustiningrum, 2016). Meskipun karyawan memeroleh kompensasi yang besar, tingkat keadilan, penghargaan hasil kerja, dan kenyamanan yang diperoleh kurang memuaskan. Ini akan menjadikan kejenuhan berkepanjangan sehingga menurunkan kinerja (Nabila \& Ratnawati, 2020).

Tingkat POS yang baik menjadikan karyawan merasa wajib memberikan timbal balik pada perusahaan sesuai kemampuan, salah satu bentuknya melalui employee engagement (Prastyo \& Frianto, 2020). Wahyuni (2019) menyatakan employee engagement adalah hubungan yang menyangkut keterikatan karyawan terhadap komitmen perusahaan dan nilai perusahaan. Karyawan akan dapat meningkatkan performa kinerjanya apabila mempunyai keterlibatan erat pada perusahaan seperti rasa kenyamanan dan mulai menyukai beberapa hal yang ada di sekitar, baik dengan tanggung jawab dan peran yang dimiliki maupun lingkungan kerjanya (Rustono \& Akbary, 2015). Atmaja (2019) menyatakan bahwa employee engagement merupakan keadaan di mana karyawan merasa ikut berpartisipasi terhadap pekerjaannya sehingga dapat berpengaruh terhadap employee performance. Saat kondisi itu diartikan bahwa perusahaan penting untuk dapat menciptakan suasana kerja yang lebih kondusif tentang rekan kerja dan perilaku atasan, memberikan fasilitas kepada karyawan, sehingga hal tersebut dapat memengaruhi employee performance.

Hali (2019) dan Lewiuci \& Mustamu (2016) menyatakan employee engagement memiliki pengaruh signifikan positif terhadap kinerja karyawan. Semakin tinggi tingkat keterikatan karyawan terhadap perusahaan maka akan membawa dampak positif terhadap hasil kerja mereka. Namun berbeda dengan Joushan et al. (2015) yang menyatakan employee engagement tidak memengaruhi kinerja karyawan secara signifikan. Hasil wawancara online kepada Bapak Merza selaku direktur utama UD. Zacyndo yang menyampaikan demi mencapai tujuan perusahaan maka dibutuhkan karyawan profesional dan berkinerja tinggi, namun yang terjadi beberapa bulan terakhir ini UD. Zacyndo mengalami penurunan kinerja karyawan bagian produksi. Hal ini ditandai dengan jumlah kapasitas produksi dari 1.000 pasang sepatu per bulan kini hanya dapat menghasilkan 800-900 pasang. Indrasari (2017:50) menjelaskan bahwa kinerja akan selalu menjadi isu aktual organisasi karena apapun bentuk organisasinya kinerja merupakan kunci terhadap efektifitas keberhasilan. UD. Zacyndo adalah perusahaan bergerak di bidang industri pembuatan sepatu safety dengan merk "OZERO" (Pabriksepatusafety.com, 2015). Penelitian ini bertujuan menguji pengaruh POS dan employee engagement terhadap kinerja karyawan.

\section{KAJIAN PUSTAKA DAN PENGEMBANGAN HIPOTESIS}

\section{Perceived Organizational Support (POS)}

POS merupakan pemikiran atau persepsi tentang seberapa jauh karyawan yakin bahwa kontribusi serta kesejahteraan mereka dihargai oleh perusahaan (Ariarni \& Afrianty, 2017). Pratiwi \& Muzakki (2021) POS diartikan sebagai dukungan dari organisasi yang dapat menggali serta memunculkan persepsi karyawan yang mana telah memberi dukungan sesuai dengan norma yang berlaku, serta harapan karyawan di perusahaan. POS dianggap sebagai keyakinan mengenai tingkat tertentu dari kewajiban organisasi terhadap karyawan (Mohamed \& Ali, 2015). Berbagai bentuk dukungan positif yang diberikan organisasi kepada karyawan contohnya dengan memberikan perlakuan secara adil, memberi persetujuan, memberikan rasa hormat, hak bersuara, gaji, promosi, media informasi dan juga bantuan lainnya yang dirasa dapat mendukung pelaksanakan pekerjaan dan kesejahteraan karyawan (Fatdina, 2009). 
Fitria et al. (2018) menyatakan terdapat tiga indikator untuk mengukur tingkat persepsi karyawan terhadap support organisasi yaitu fairness atau keadilan procedural yang dapat melibatkan tata cara perusahaan untuk menilai kontribusi karyawan, supervisor support atau dukungan atasan ditandai persepsi karyawan yang melibatkan penilaian mereka terhadap organisasi yang peduli terhadap kesejahteraan karyawan serta penghargaan dan kondisi kerja.

\section{Employee Engagement}

Employee engagement merupakan suatu hubungan yang menunjukkan keterkaitan karyawan terhadap nilai-nilai dan komitmen organisasi (Wahyuni, 2019). Joushan et al. (2015) menyatakan employee engagement sebagai bentuk keterkaitan karyawan pada tingkat emosional terhadap organisasi. Kemudian Cintani \& Noviansyah (2020) employee engagement merupakan bentuk sukarela karyawan yang menjadi acuan dalam promosi perusahaan, membeli maupun berinvestasi terhadap perusahaan. Lewiuci \& Mustamu (2016) menyatakan employee engagement atau rasa keterikatan dari seorang karyawan bisa memengaruhi tingkat kinerjanya. Oleh karena itu, jika seorang karyawan mempunyai rasa keterlibatan kuat pada pekerjaannya tujuan perusahaan akan lebih mudah dicapai.

Tiga indikator employee engagement menurut Hali (2019) yaitu semangat karyawan yang ditunjukkan melalui energi dalam bekerja (vigor), dedikasi karyawan yang melibatkan rasa ingin terlibat dan ketertarikan terhadap pekerjaan yang diberikan (dedication), serta penyerapan yang menandakan karyawan fokus dan mendalami pekerjaannya (absorption).

\section{Kinerja Karyawan}

Fitria et al. (2018) menjelaskan bahwa kinerja merupakan output pekerjaan nyata yang telah diraih oleh karyawan di perusahaan selaras dengan tugas dan tanggung jawab. Kinerja karyawan yaitu output yang dihasilkan seperti efisiensi dan efektivitas dalam bekerja (Agustiningrum, 2016). Selanjutnya menurut Cintani \& Noviansyah (2020), kinerja karyawan ialah hasil pekerjaan yang telah diselesaikan oleh karyawan atau perilaku sesungguhnya diwujudkan sesuai peranannya dalam perusahaan. Kinerja karyawan dapat dilihat dengan tercapainya visi dan misi perusahaan (Mursidta, 2017). Kinerja karyawan sangat penting diperhatikan sebagai suatu langkah untuk menuju pada proses tercapainya tujuan organisasi melalui keuletan dan profesionalisme sesuai dengan tugas dan tanggung jawab (Indrasari, 2017:51). Oleh karena itu, dibutuhkan ketentuan kriteria yang terukur dan jelas sebagai pedoman yang sebelumnya sudah ditetapkan bersama-sama. Ada empat indikator sebagai tolak ukur kinerja karyawan menurut Siswono \& Sim (2016) yaitu kualitas, kuantitas, pelaksanaan tugas, dan tanggung jawab usaha.

\section{Hubungan antar Variabel}

Dukungan organisasi dipandang sebagai komitmen organisasi pada karyawan apabila secara umum menghargai dedikasi dan loyalitas sehingga memberikan kinerja terbaik di luar tugas-tugas resminya karena merasa bahwa organisasi memberikan dukungan atau hal-hal yang diharapkan (Fatdina, 2009). Fitria et al. (2018) membuktikan adanya pengaruh langsung dan signifikan antara POS terhadap kinerja karyawan. Didukung oleh Mursidta (2017), secara parsial POS mampu memengaruhi signifikan terhadap kinerja karyawan. Pratiwi \& Muzakki (2021) juga membuktikan bahwa terdapat pengaruh positif antara POS dan kinerja karyawan. Namun, Wahyuni (2019) menyatakan kinerja karyawan dipengaruhi tidak signifikan oleh POS. Karyawan merasa ada saran yang di sampaikan ke perusahaan belum semuanya mendapatkan respon yang baik dan cepat.

\section{H1: POS berpengaruh signifikan positif terhadap kinerja karyawan.}

Perhatian terhadap employee engagement (keterikatan karyawan) saat ini disebabkan karena bagaiamana employee engagement menghasilkan kinerja yang tinggi bagi perusahaan (Adi \& Noora, 2018). Hali (2019) menunjukkan employee engagement memiliki pengaruh signifikan positif terhadap kinerja karyawan. Begitu juga Cintani \& Noviansyah (2020) menjelaskan pengaruh signifikan antara employee engagement terhadap kinerja karyawan. Lewiuci \& Mustamu (2016) juga mendukung pengaruh positif dan signifikan antara employee engagement terhadap kinerja karyawan. Berbeda dari 
Septi Diana \& Agus Frianto. Pengaruh Perceived Organizational Support dan Employee Engagement terhadap Kinerja Karyawan

Joushan et al. (2015) employee engagement tidak memengaruhi kinerja karyawan secara signifikan. Meski demikian, perusahaan tetap berupaya untuk memperhatikan employee engagement guna meningkatkan kinerja karyawan.

$\mathrm{H} 2$ : Employee engagement berpengaruh positif dan signifikan terhadap kinerja karyawan.

Atmaja (2019) menunjukkan POS berpengaruh signifikan terhadap employee performance, POS berpengaruh signifikan terhadap employee engagement dan employee engagement berpengaruh signifikan terhadap employee performance. Begitupun Ariarni \& Afrianty (2017) membuktikan POS dan employee engagement memengaruhi kinerja karyawan. Nabila \& Ratnawati (2020) menyatakan POS dan employee engagement berpengaruh positif dan signifikan terhadap kinerja karyawan.

H3: POS dan employee engagement berpengaruh signifikan positif terhadap kinerja karyawan.

Kerangka konseptual yang di gunakan untuk mengetahui pengaruh POS dan employee engagement terhadap kinerja karyawan pada pabrik sepatu safety UD. Zacyndo ditunjukkan pada Gambar 1.

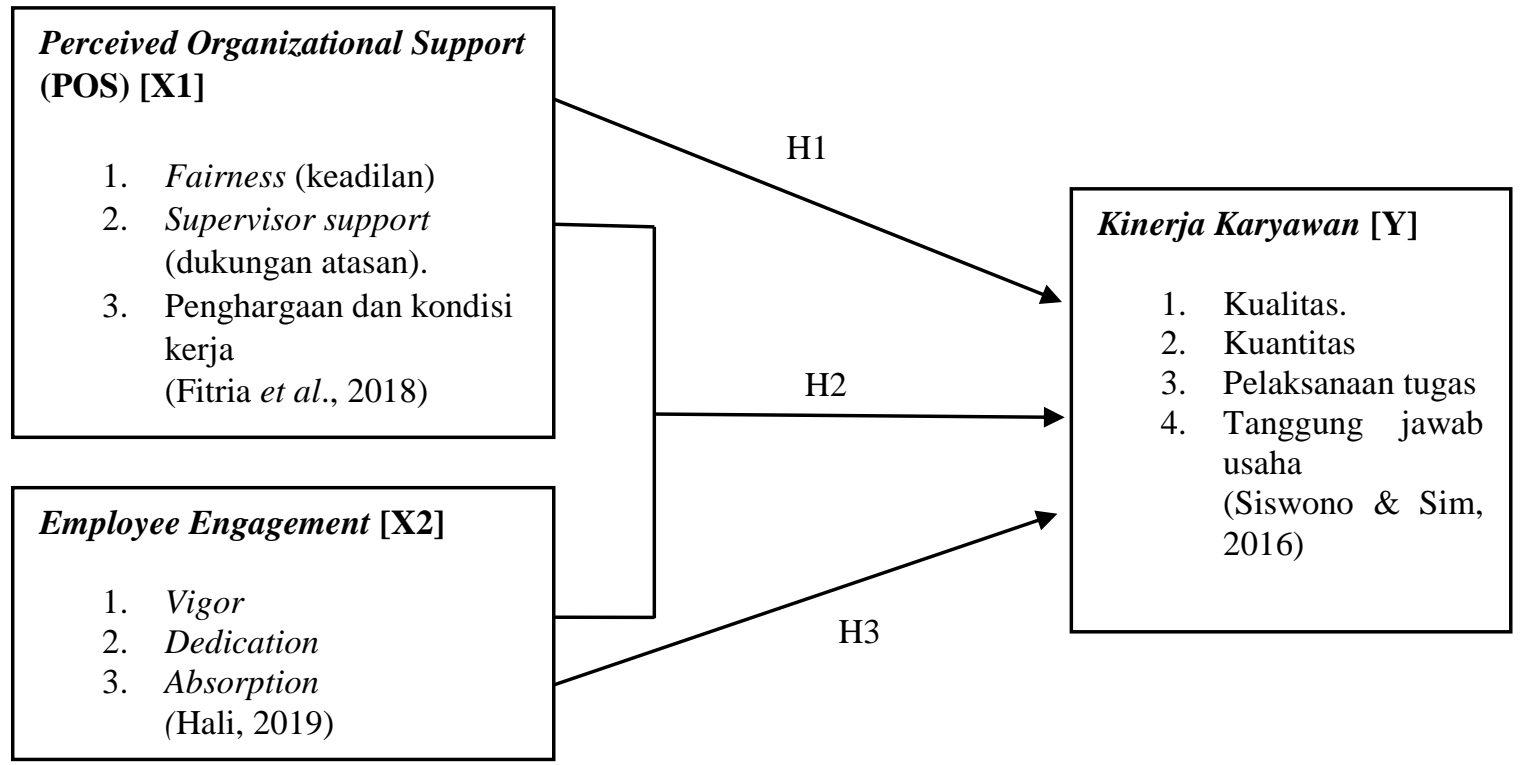

Gambar 1. KERANGKA KONSEPTUAL

\section{METODE PENELITIAN}

Penelitian ini merupakan penelitian kuantitatif. Penelitian dilakukan pada pabrik sepatu safety UD. Zacyndo yang berada di Tuban dan Mojokerto. Populasi adalah karyawan tetap UD. Zacyndo. Jumlah sampel dalam penelitian ini adalah 45 orang. Data dikumpulkan dengan angket online dengan rating scale berawal dari angka satu (sangat tidak setuju) hingga angka lima (sangat setuju). Teknik analisis data yang digunakan yaitu regresi linear berganda menggunakan SPSS versi 24.

\section{HASIL DAN PEMBAHASAN}

\section{Hasil Uji Validitas}

Tolak ukur untuk mengetahui valid atau tidak pernyataan yang ada di kuesioner dengan dilakukannya pengujian validitas. Hasil analisis menunjukkan semua komponen pernyataan dikatakan valid dengan nilai signifikansinya di bawah propabilitas 0,05 dan diperkuat dengan lebih besarnya nilai $r$ hitung dibandingkan nilai pada $\mathrm{r}$ tabel yaitu 0,291 .

\section{Hasil Uji Reliabilitas}

Uji reliabilitas digunakan sebagai alat ukur untuk menetapkan dan mengetahui apakah pernyataan dalam kuesioner dapat dipergunakan lebih dari sekali untuk responden yang sama maupun berbeda. 
Cronbach's Alpha digunakan untuk menguji tingkat keandalan atau reliabilitas dari masing-masing indikator variabel. Nilai Cronbach's Alpha sebesar 0,840 lebih besar 0,60. Sehingga 29 pernyataan yang digunakan variabel POS, employee engagement dan kinerja karyawan adalah sangat reliabel dan konsisten.

\section{Hasil Uji Asumsi Klasik}

Pada Tabel 1, hasil uji normalitas dilakukan menggunakan Kolmogrov-smirnov (KS) dengan nilai 0,2 sehingga diperoleh data berdistribusi normal karena $0,2>0,05$. Uji autokorelasi dengan menggunakan Durbin-watson (DW) menghasilkan 1,440 dengan derajat kepercayaan 5\% $(\alpha=0,05)$, dengan jumlah variabel independen (k) sebanyak 2 dan (n) 45. Maka, persamaan $\mathrm{dL}<\mathrm{d}<\mathrm{du}$ yaitu $1,4298<1,440<1,6148$. Artinya, tidak ditemukan autokorelasi. Uji multikolonieritas menunjukkan nilai tolerance $>0,1$ dari keseluruhan variabel independen dan hasil VIF $<10$, maka tidak terindikasi multikolinieritas. Uji heterokedastisitas melalui scatterplot dapat dilihat pada Gambar 2. Titik pada sumbu Y menyebar luas di atas serta di bawah nol dan tidak terbentuk pola tertentu. Nilai signifikansi dari semua variabel independen $>0,05$ dengan artian bebas dari gejala heteroskedastisitas.

Tabel 1.

HASIL UJI ASUMSI KLASIK

\begin{tabular}{ccccccc}
\hline Variabel & $\boldsymbol{R}$ Square & Coefficient B & T & Sig. & f & Sig. \\
\hline & 0,195 & 29,066 & 4,203 & 0 & & \\
(Constant) & & 0,023 & 0,135 & 0,893 & 5,099 &, $010^{\mathrm{b}}$ \\
POS & & 0,577 & 2,601 & 0,013 & &
\end{tabular}

Employee Engagement

Sumber: Output SPSS (2021, data diolah)

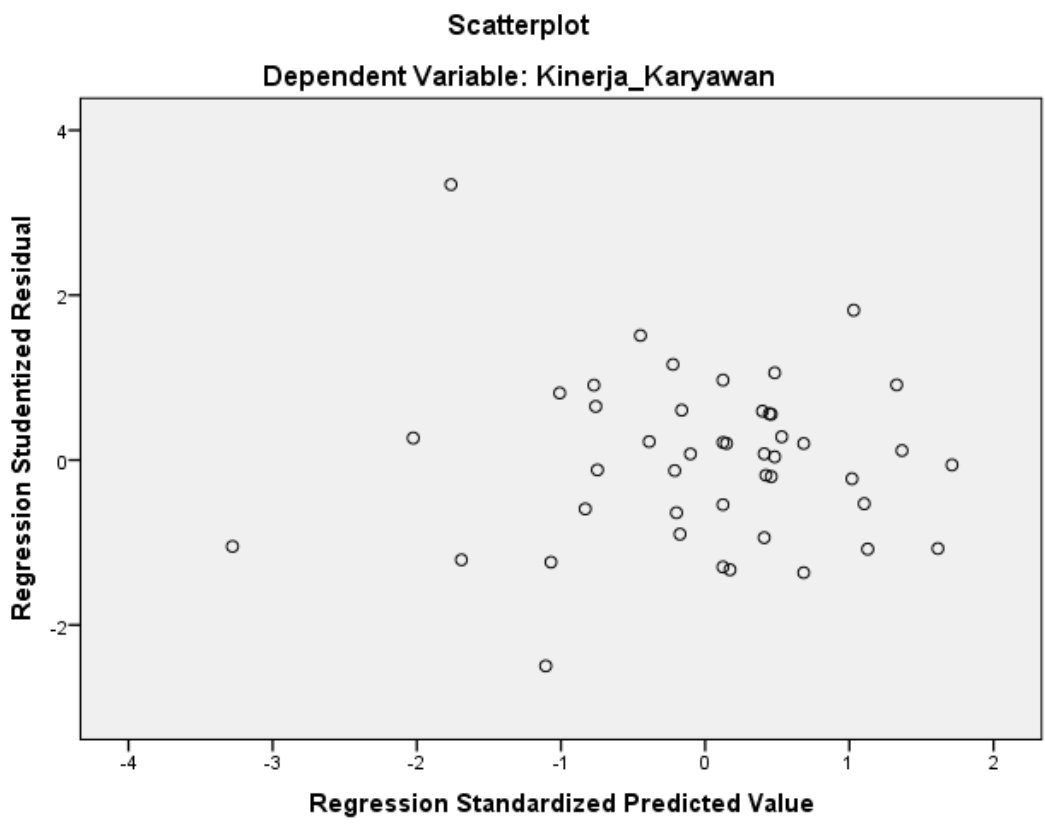

Sumber: Output SPSS (2021, data diolah)

\section{Gambar 2. OUTPUT SCATTERPLOT}

\section{Hasil Uji Regresi Linear Berganda}

Berdasarkan Tabel 2, hasil pengujian pengaruh variabel POS dan employee engagement terhadap kinerja karyawan dengan menggunakan uji regresi linear berganda menunjukkan nilai unstandardized coefficients (a) memiliki nilai sebesar 29,066. Hasil tersebut menunjukkan jika X (POS dan employee engagement) adalah konstan atau X1, X2 sama dengan 0 , volume besaran tingkat kinerja karyawan sebesar 29,066. Nilai variabel POS terhadap kinerja karyawan adalah 0,023. Artinya, apabila variabel 
Septi Diana \& Agus Frianto. Pengaruh Perceived Organizational Support dan Employee Engagement terhadap Kinerja Karyawan

terikat yaitu kinerja karyawan meningkat 1 nilai, variabel perceived organizational support akan naik juga menjadi 0,023. Begitu juga pada variabel bebas employee engagement pada kinerja karyawan bernilai 0,577. Jadi, apabila variabel terikat yaitu kinerja karyawan meningkat 1 nilai, variabel employee engagement akan naik pada 0,577. Koefisien variabel bebas bertanda positif artinya terjadi pengaruh positif antara variabel POS dan employee engagement terhadap kinerja karyawan. Dengan demikian, peningkatan variabel POS dan employee engagement akan diikuti oleh naiknya tingkat kinerja karyawan.

Tabel 2.

HASIL UJI LINEAR BERGANDA

\begin{tabular}{ccccccc}
\hline Variabel & $\boldsymbol{R}$ Square & Coefficient B & $\boldsymbol{T}$ & Sig. & $\boldsymbol{f}$ & Sig. \\
\hline & 0,195 & 29,066 & 4,203 & 0 & & \\
(Constant) & & 0,023 & 0,135 & 0,893 & 5,099 &, $010^{\mathrm{b}}$ \\
POS & & 0,577 & 2,601 & 0,013 & \\
Employee Engagement & & & 1 & & & \\
\hline
\end{tabular}

Sumber: Output SPSS (2021, data diolah)

\section{Koefisien Determinasi (R2)}

Besarnya kombinasi variabel independent memengaruhi variabel dependen dapat di ukur dengan nilai $\mathrm{R}^{2}$ yang berada diantara nilai 0 dan 1 . Jika nilai tersebut mendekati angka 0 , hubungan antar variabel tersebut semakin melemah. Namun, apabila nilai mendekati angka 1, model yang dihasilkan oleh regresi itu semakin bagus. Pada Tabel 2, R Square bernilai 0,195. Artinya, variabel POS dan employee engagement dapat menjelaskan variabel kinerja karyawan senilai $19,5 \%$ sedangkan $80,5 \%$ lainnya dipengaruhi variabel lain.

\section{Uji F}

Tujuan penggunaan uji $\mathrm{F}$ adalah melihat keseluruhan dari variabel indipenden dalam memengaruhi variabel dependennya (Ghozali, 2016:48). Tabel 2 menunjukkan nilai signifikannya yaitu $0,010<0,05$ dan F hitung 5,099 > F tabel 1,89. Jadi, variabel dependen dipengaruhi oleh keseluruhan variabel independen secara signifikan.

\section{Uji T (Uji Parsial)}

Uji T dipergunakan sebagai alat ukur hubungan dan besarnya pengaruh antar variabel secara parcial. Jika nilai signifikansi menunjukkkan nilai $<0,05$ artinya adanya pengaruh signifikan antara variabel independen terhadap variabel dependen. Tabel 2 menunjukkan variabel POS memiliki signifikan senilai $0,893>0,05$ sehingga variabel POS tidak berpengaruh signifikan terhadap variabel kinerja karyawan. Jika nilai thitung $0,135<$ dari t tabel yaitu 1,678, variabel perceived organizational support secara parsial tidak memiliki hubungan signifikan terhadap kinerja karyawan. Employee engagement memiliki nilai $0,013<0,05$ artinya variabel employee engagement berpengaruh signifikan pada variabel kinerja karyawan. t hitung senilai 2,601> 1,678 berarti secara parsial variabel employee engagement memiliki hubungan yang signifikan pada kinerja karyawan.

\section{Pengaruh Perceived Organizational Support terhadap Kinerja Karyawan}

Dari output pengujian diketahui bahwa POS terbukti tidak pengaruh signifikan pada kinerja karyawan. Hasil ini mendukung Wahyuni (2019) yang membuktikan POS memiliki pengaruh tidak signifikan terhadap kinerja karyawan. Namun, bertolak belakang dengan Pratiwi \& Muzakki (2021), Fitria et al. (2018), dan Mursidta (2017) yang menyatakan POS mempunyai pengaruh positif dan signifikan terhadap kinerja karyawan. Dari hasil wawancara yang dilakukan pada karyawan bagian produksi UD. Zacyndo menyatakan ada beberapa pendapat dan masukan yang diberikan belum mendapat respon yang cepat. Bagian produksi memaksimalkan dengan baik tugas dan tanggungjawab mereka agar sesuai target yang diberikan perusahaan akan tetapi tidak didukung dengan sarana dan prasarana yang ada. Misalnya, keterlambatan bahan baku dan kurangnya kapasitas mesin produksi sehingga yang terjadi dilapangan mereka harus rela mengantri dengan yang lain untuk dapat tetap menghasilkan pekerjaan sesuai target. Karyawan beberapa kali sudah memberikan saran kepada 
perusahaan agar jangan sampai bahan baku telat dengan cara membuat catatan stok bahan baku namun hal itu belum terealisasi dengan baik. Karyawan juga telah memberikan masukan untuk pengadaan alat mesin produksi baru, namun respon dari perusahaan juga lama bahkan harus menunggu beberapa tahun agar terealisasi.

\section{Pengaruh Employee Engagement terhadap Kinerja Karyawan}

Hasil uji dapat diketahui employee engagement memikiki pengaruh positif dan signifikan terhadap kinerja karyawan. Ini mendukung Hali (2019) yang menyatakan employee engagement mempunyai pengaruh positif dan signifikan terhadap kinerja karyawan. Cintani \& Noviansyah (2020) dan (Lewiuci \& Mustamu, 2016) juga membuktikan adanya pengaruh yang signifikan antara variabel employee engagement terhadap kinerja karyawan. Akan tetapi, hasil penelitian ini tidak selaras dengan Joushan et al. (2015) bahwa employee engagement tidak ada pengaruh signifikan terhadap kinerja karyawan.

Melalui wawancara online dengan Udin staff produksi divisi stitching yang sudah bekerja selama 5 tahun, diketahui bahwa peningkatan jabatan dilakukan secara adil dan merata, semua mempunyai kesempatan yang sama untuk mendapatkan peningkatan jabatan berdasarkan kinerja karyawan. Dengan demikian, karyawan menjadi lebih bersemangat untuk berlomba-lomba meningkatkan kinerja dengan selalu berusaha menghasilkan pekerjaan sesuai target bahkan bisa lebih. Akan tetapi, dalam wawancara online tersebut Udin juga menyampaikan beberapa karyawan lain masih kurang setuju dengan kebijakan lembur yang dibuat di perusahaan yang mana kebijakan tersebut selalu mengalami perubahan. Oleh karena itu, UD. Zacyndo masih terus berupaya untuk memperhatikan penerapan employee engagement agar dapat terus mendorong peningkatan kinerja karyawannnya secara maksimal.

\section{Pengaruh Perceived Organizational Support dan Employee Engagement terhadap Kinerja Karyawan}

Berdasarkan uji yang telah dilakukan, POS dan employee engagement memengaruhi secara positif dan signifikan terhadap kinerja karyawan di UD. Zacyndo. Penelitian ini mendukung Atmaja (2019) yang membuktikan POS memengaruhi employee performance secara signifikan, POS dan employee engagement memengaruhi employee performance secara signifikan. Begitupun Ariarni \& Afrianty (2017) dan Nabila \& Ratnawati (2020) juga menunjukkan POS dan employee engagement berpengaruh positif pada kinerja karyawan.

Hasil wawancara online kepada Asrofil salah satu staff divisi sol di UD. Zacyndo, menyatakan solidaritas antar karyawan sangat tinggi, saling membantu satu dengan yang lain sehingga bekerja merasa nyaman dan bersemangat memperoleh kinerja terbaik meskipun dalam kebijakan perusahaan ada beberapa yang belum tepat seperti ketentuan waktu lembur. Oleh karena itu, UD. Zacyndo harus dapat terus memerhatikan POS dan employee engagement agar meningkatkan kinerja karyawan.

\section{KESIMPULAN}

Kinerja karyawan pabrik sepatu safety UD. Zacyndo secara parsial tidak dipengaruhi oleh POS. Tingkat kinerja karyawan pada UD. Zacyndo tidak terpengaruh dengan ada tidaknya POS. Employee engagement memiliki pengaruh dan signifikan pada tingkat kinerja karyawan UD. Zacyndo. Semakin besar employee engagement yang dimiliki oleh karyawan UD. Zacyndo, semakin tinggi pula tingkat kinerja. POS dan employee engagement juga berpengaruh signifikan terhadap kinerja karyawan pabrik sepatu safety UD. Zacyndo. Semakin baik POS dan employee engagement terhadap perusahaan UD. Zacyndo, semakin meningkat kinerja karyawan.

Perusahaan disarankan untuk meningkatkan POS dan employee engagement dalam perusahaan yang juga akan berdampak pada kinerja karyawan dan selanjutnya dapat mempermudah pencapaian visi organisasi. Salah satu yang perlu diperhatikan dalam meningkatkan POS adalah dengan memperhatikan pemberian gaji kepada karyawan agar mereka terpuaskan atas penghasilan yang di 
Septi Diana \& Agus Frianto. Pengaruh Perceived Organizational Support dan Employee Engagement terhadap Kinerja Karyawan

dapat sehingga mendorong semangat kerja dan menghasilkan kinerja yang maksimal. Untuk menjaga dan meningkatkan rasa keterikatan karyawan, perusahaan perlu membuat kebijakan tertulis tentang bekerja di luar jam kerja (lembur). Perusahaan dapat membuat prosedur yang jelas mengenai jam lembur dan juga upah yang akan diberikan. Selain itu, perusahaan juga dapat lebih memperhatikan kesehatan dan kebahagiaan karyawannya dengan cara memberikan makanan sehat dan sesekali memberikan fasilitas olahraga agar karyawan tidak stres, kelelahan dan sakit. Perusahaan hendaknya membiasakan karyawaan membuat to do list atau daftar tugas yang harus diselesaikan hari itu sehingga dapat melatih karyawan untuk bisa lebih memperhitungkan pekerjaan mereka agar sesuai dengan target kerja yang telah ditetapkan perusahaan UD. Zacyndo. Penelitian selanjutnya dapat melibatkan motivasi kerja dan jenjang karir.

\section{DAFTAR PUSTAKA}

Agustiningrum, Sherly. Dwi. (2016). Pengaruh Persepsi Dukungan Organisasi terhadap Kinerja Karyawan yang Dimediasi oleh OCB (Organizational Citizenship Behavior) (Studi pada PT.Angkasa Pura I Kantor Cabang Surabaya). Jurnal Ilmu Manajemen (JIM), 4(2), 212-225.

Mohamed, S. A. \& Ali, M. (2015). The Influence of Perceived Organizational Support on Employees' Job Performance. International Journal of Scientific and Research Publications, 5(4), 1-6. Retrieved from www.ijsrp.org

Rustono, A., \& Akbary, M. F. (2015). Pengaruh Employee Engagement terhadap Kinerja Karyawan Dana Pensiun (Dapen) Telkom Bandung. e-Proceedings of Management, 2(2), 1172-1178. Retrieved from www.businessjournal.gallup.com

Aziz, A. R. (2018). Evaluasi Kinerja Pegawai dalam Meningkatkan Kemandirian Anak Cacat Tuna Netra pada Unit Pelaksana Teknis Dinas Panti Rehabilitas Penyandang Cacat Netra Provinsi Sumatera Selatan. Jurnal Ilmu Administrasi dan Studi Kebijakan (JIA SK), 1(20), 11-23.

Ariarni, N., \& Afrianty, T. W. (2017). Pengaruh Perceived Organizational Support terhadap Kinerja Karyawan Dengan Employee Engagement Sebagai Variable Intervening (Studi pada Karyawan PT. Pos Indonesia Kota Madiun). Jurnal Administrasi Bisnis, 50(4), 169-177.

Atmaja, J. P. W. (2019). Pengaruh Perceived Organizational Support terhadap Employee Performance melalui Employee Engagement CV. Sumo Surya Perkasa di Lombok. Agora, 7(1),1-6.

Cintani, C., \& Noviansyah, N. (2020). Pengaruh Employee Engagement terhadap Kinerja Karyawan pada PT. Sinar Kencana Multi Lestari. Kolegial, 8(1), 29-44.

Fatdina. (2009). Peran Dukungan Organisasi yang Dirasakan Karyawan sebagai Mediator Pengaruh Keadilan Prosedural terhadap Perilaku Kewarganegaraan Organisasi. Jurnal Psikologi, 36(1), $1-17$.

Adi, A. N., \& Noora, F. (2018). Employee Engagement pada Sektor Bisnis dan Publik. Malang: CV. IRDH (Reseach \& Punlishing).

Fitria, AA. Susilo, Heru \& Sulistyo, CW, (2018). Pengaruh Perceived Organizational Support (POS) terhadap Komitmen Organisasional dan Kinerja Karyawan (Studi pada Karyawan Bagian Produksi CV. Dwi Putra Perkasa Garment). Jurnal Administrasi Bisnis, 56(1), 179-186.

Ghozali, I. (2016). Aplikasi Analisis Multivariete dengan Program IBM SPSS 23. Semarang: Badan Penerbit Universitas Diponegoro.

Hali, M. A. (2019). Pengaruh Employee Engagement terhadap Kinerja Karyawan melalui Komitmen Organisasi (Studi pada Divisi Produksi PT. Indo Putra Harapan Sukses Makmur). Jurnal Ilmu 
$\begin{array}{lllll}\text { Manajemen } & \text { (JIM), } & 7(1), & \text { 228-234. } & \text { Retrieved }\end{array}$ https://jurnalmahasiswa.unesa.ac.id/index.php/jim/article/view/25466

Indrasari, D. M. (2017). Kepuasan Kerja dan Kinerja Karyawan Tinjauan dari Dimensi Iklim Organisasi, Kreatifitas Individu, dan Karakteristik Pekerjaan. Yogyakarta: Indomedia Pustaka.

Saretta, I. R. (2019). Manajemen Sumber Daya Manusia sebagai Upaya Mencapai Target Organisasile. Cermati.com. Retrieved from (https://www.cermati.com/artikel/manajemensumber-daya-manusia-sebagai-upaya-mencapai-target-organisasi, diakses 20 Maret 2021).

Joushan, SA. Syamsun, M. \&Kartika, Lindawati (2015). Pengaruh Budaya Organisasi dan Employee Engagement terhadap Kinerja Karyawan pada PT. PLN (Persero) Area Bekasi. Jurnal Aplikasi Manajemen, 13(66), 697-703.

Mursidta, S. (2017). Pengaruh Perceived Organizational Support (Persepsi Dukungan Organisasi) dan Kepuasan Kerja terhadap Kinerja Karyawan pada PT. Varia Usaha Beton Gresik. Jurnal Ilmu Manajemen (JIM), 5(1), 1-12.

Lewiuci, P. G., \& Mustamu, R. H. (2016). Pengaruh Employee Engagement terhadap Kinerja Karyawan pada Perusahaan Keluarga Produsen Senapan Angin. Agora Journal, 4(2), 101-107.

Nabila, H. A., \& Ratnawati, I. (2020). Pengaruh Persepsi Dukungan Organisasi terhadap Kinerja Karyawan dengan Keterikatan Karyawan dan Perilaku Kerja Proaktif sebagai Variabel Intervening (Studi pada PT. Kereta Api Indonesia (Persero) Daop IV Semarang) Hasna. Diponegoro Journal of Management, 9, 1-125. Retrieved from http://ejournals1.undip.ac.id/index.php/dbr

Nadeak, B. (2019). Manajemen Pelatihan dan Pengembangan. Jakarta: UKI Press. Retrieved from http://repository.uki.ac.id/id/eprint/1308

Pabriksepatusafety.com. (2015). Tentang UD. Zacyndo. Retrieved from (http://www.pabriksepatusafety.com/2015/02/foto-pabrik.html, diakses 20 Februari 2021).

Prastyo, B., \& Frianto, A. (2020). Pengaruh Perceived Organizational Support terhadap Kinerja Karyawan melalui Employee Engagement : sebuah Studi Literatur. BIMA: Journal of Busniness and Innovation Management, 3(1), 59-72. Retrieved from https://ejournal.feunhasy.ac.id/bima/article/view/310

Pratiwi, A. R., \& Muzakki. (2021). Perceived Organizational Support terhadap Komitmen Organisasi dan Kinerja Karyawan. Jurnal Ilmiah Manajemen Dan Bisnis, 22(1), 111-120. Retrieved from http://jurnal.umsu.ac.id/index.php/mbisnis\%0APerceived

Santoso, A. R., \& Mangundjaya, W. L.H. (2018). Pengaruh Persepsi Dukungan Organisasi terhadap Komitmen Afektif untuk Berubah Studi Kasus pada Kementerian PUPR yang sedang Mengalami Perubahan Reformasi Birokrasi. Jurnal Infrastruktur, 4(1), 53-60.

Siswono, D. \& Sim. (2016). Pengaruh Employee Engagement terhadap Kinerja Karyawan di Rodex Travel Surabaya. Agora Journal, 4(2), 374-380.

Wahyuni, R. A. (2019). Perceived Organizational Support dan Talent Management terhadap Kinerja Karyawan melalui Employee Engagement. Jurnal Ilmu Manajemen, 7(4), 905-913.

Wahyani, W. (2020). Aset Penting yang Wajib Dijaga oleh Suatu Organisasi maupun Perusahaan. IPOMS. Retrieved from (https://www.ipomssurabaya.com/aset-penting-yang-wajib-dijagaoleh-suatu-organisasi-maupun-perusahaan/, diakses 1 Maret 2021). 